\title{
Investigation of Strong Strata Behaviors in the Close-Distance Multiseam Coal Pillar Mining
}

\author{
Hongwei Mu $\mathbb{D},,^{1,2}$ Yongsheng Bao, ${ }^{3}$ Dazhao Song $\mathbb{D},{ }^{1,2}$ and Dongfang Su ${ }^{1,2}$ \\ ${ }^{1}$ School of Civil and Resource Engineering, University of Science and Technology Beijing, Beijing 100083, China \\ ${ }^{2}$ State Key Laboratory of the Ministry of Education of China for High-Efficient Mining and Safety of Metal Mines, \\ University of Science and Technology Beijing, Beijing 100083, China \\ ${ }^{3}$ Datong Coal Mine Group Co., Ltd., Datong 037003, China \\ Correspondence should be addressed to Hongwei Mu; muhongwei219@163.com
}

Received 6 February 2020; Revised 7 January 2021; Accepted 25 January 2021; Published 5 February 2021

Academic Editor: Weiqiang Wang

Copyright (C) 2021 Hongwei Mu et al. This is an open access article distributed under the Creative Commons Attribution License, which permits unrestricted use, distribution, and reproduction in any medium, provided the original work is properly cited.

\begin{abstract}
According to the new stress distribution pattern and the strong strata behaviors as the characteristics of the coal pillars in the closedistance multiseam coal pillar mining, the common characteristics of different types of overlying coal pillars were summarized and analyzed. Moreover, a theoretical model for the mechanism of strong strata behaviors in the close-distance multiseam coal pillar mining was established, which was validated by the monitoring data of seismic computed tomography CT, microseism, and electromagnetic radiation (EMR). Furthermore, the results of the study indicated that the main factors affecting the strong strata behaviors were the static stress concentration caused by the overlying coal pillars and the dynamic disturbance caused by the fracturing and slipping of the overlying coal pillars and roof under the influence of mining. In the case of Xinzhouyao coal mine, the transmitted stress and lateral support pressure of the overlying coal pillars accounted for $78.3 \%$ and $16 \%$ of the vertical concentrated stress, respectively, and the areas closer to the overlying coal pillars were more susceptible to dynamic load disturbances. The monitoring results of seismic computed tomography CT and EMR demonstrated the static load stress concentration area was distributed near the overlying coal pillar, and the stress concentration degree was greater in the area of superimposed lateral support pressure and advanced support pressure. Moreover, microseismic spatial positioning revealed that the high-energy microseismic events were mainly concentrated near the overlying large coal pillars and roof. The on-site multiparameter detection results were highly consistent with the characteristics of actual strata behaviors and the conclusions of the theoretical model. This method could provide a reference for the quantitative calculation of stress distribution under similar conditions and the identification of the danger zone of strata behaviors.
\end{abstract}

\section{Introduction}

The close-distance coal seam refers to the adjacent coal seams that have significant mutual influence during the mining process. The coal pillars bear the pressure of the overlying strata and transmit it to the bottom rock stratum, which leads to the redistribution of the bottom rock stratum stress. Repeated disturbances in close-distance multiseam coal mining further exacerbate the complexity of stress environment. New characteristics of stress and danger zone distribution have emerged $[1,2]$, which is a primary reason causing the difficulty to predict the danger zones with strong strata behaviors in close-distance multiseam coal pillar mining. The number of long-wall and multiseam mining coal mines in China and around the world is rapidly increasing [3-9]. Existing theories are not enough to support and solve the new rockburst situation we are facing now. Therefore, it is urgent to study the mechanism of strong strata behaviors under the condition of close-distance multiseam coal pillar mining and provide theoretical support for the detection of the danger zone with strong strata behaviors.

The strong strata behavior is a slow or sudden release of a large amount of energy accumulated in the coal rock mass, which in general results in the damage of the coal rock mass, human casualties, and damage of mines and equipment $[10,11]$. At present, the characteristics and laws of the strata 
behaviors of single-seam mining have been studied. Yin and Han et al. studied the stress concentration caused by the mining and structure of the working face from the aspects of theoretical calculation, numerical simulation, and similar material physical simulation technology [12-16]. Ye and Wang et al. studied the movement rule and dynamic disturbance of single-seam overburden [17-19]. In recent years, scholars in the field of mining begin to pay attention to a series of problems caused by multiseam mining. Wang and Yang and $\mathrm{He}[20,21]$ summarized the law of the strata behaviors when the working face crossed the concentrated coal pillars through field observation and other methods and proposed corresponding countermeasures. Ju et al. [22-24] used theoretical analysis and simulation experiments to investigate the mechanism and law of dynamic loading pressure from the point of the instability of the fracture structure of the key layer above the coal pillar. Gao et al. [25] numerically simulated the horizontal and vertical distance between different working faces and overlying remaining coal pillars, and the stress distribution in the process of coal mining under different buried depth conditions. Suchowerska et al. [5] calculated the changes in vertical stress in multiseam coal mining in longwall working faces by using numerical simulations. Yu [26] numerically simulated the structural evolution of overburden roofs in multiple coal seams and the influence of remaining coal pillars on strong strata behaviors in the lower coal seams. Adhikary et al. [27] studied the applicability of FLAC2D and FLAC3D in numerical simulation of multiseam mining. Ghabraie et al. [28] simulated the law of overburden collapse in multiseam coal pillar mining by means of laboratory physical simulation technology. Tian et al. [29] and Huang and Cao [30] also used physical simulation technology to study the roof strata movement and coal pillar instability in the process of multiseam mining. Sun et al. [31] studied the stability of the overlying remaining coal pillars by using the elastic-plastic theory and the slip line field theory. According to the particularity of multiseam mining, Shen et al. [32] established the energy density risk index to evaluate the risk of multiseam mining by using the microseismic data. Previous studies have shown that overlying coal pillars under the condition of close-distance multiseam coal pillars were the main factor causing disaster. The current research is mainly based on field experience summary, numerical simulation, and theoretically qualitative interpretation. However, the studies on the mechanism of strong strata behaviors in closedistance multiseam coal pillar mining through theoretical model quantitative calculation and multiparameter monitoring data have been seldom reported. Considering that timely and effective numerical simulation is always difficult for mining corporations, there is an urgent need to provide a theoretical model for mining enterprises to effectively and quantitatively estimate the static stress of multiseam mining and identify the dangerous zone of strata behavior and provide guidance for the selection of rock deformation prevention methods and specific pressure relief measures.

Based on the existing studies on the characteristics and laws of strong strata behaviors in close-distance multiseam coal pillar mining, we conducted in-depth theoretical studies on the mechanism of strata behaviors under this condition and validated the study result according to field geophysical signals. According to the summary of the characteristics of different types of overlying coal pillars and the strata behaviors, a theoretical model of the mechanism of strata behaviors in close-distance multiseam coal pillar mining was established. Moreover, the theoretical model was validated by comprehensive monitoring methods, including seismic computed tomography CT, microseismic monitoring, and EMR, which provide a reference for the quantitative calculation of stress distribution under similar conditions and the identification of the danger zone with strata behaviors.

\section{Classification of Close-Distance Multiseam Coal Pillars and Characteristics of Strata Behaviors}

In the process of multiseam coal mining, the upper coal seam is generally mined earlier. Due to the limitation of geological structure and mining technology, the layout of the upper coal seam is irregular, and its impact on the lower coal seam had not been fully considered, which causes potential safety hazard for the mining on the ultralong and widened highmining fully mechanized working faces.

According to the positional relationship with the strike direction of the working face, the types of coal pillars in the close-distance multiseam mining are divided into four categories: parallel coal pillars, diagonal coal pillars, vertical coal pillars, and irregular coal pillars. Among them, parallel coal pillars run parallel to the working face. According to the positional relationship between the overlying coal pillars and the roadway on the lower working face, they can be divided into overlapping type, inward-stagger type, and outwardstagger type, such as the Malan mine and Shangwan mine [32]. Diagonal coal pillars intersect with the lower working face at different angles, such as Xinzhouyao mine and Sanhejian mine [33]. Vertical coal pillars are perpendicular to the direction of the working face, such as Daliuta mine $[22,24]$. Irregular coal pillars are represented by the point coal pillars reserved in Tashan mine [25] and the scar coal pillars reserved in Sanhejian mine [34]. The spatial relationship between the four types of overlying coal pillars and the lower working face is shown in Figure 1.

The sources of strata behaviors in the close-distance multiseam coal pillar mining can be divided into static load and dynamic disturbance. Their characteristics are as follows: static load concentrated in the roadway causes roof subsidence and deformation of the two sides, as well as fatigue damage to the support of the working face. On the other hand, dynamic disturbance is caused by the mining of the lower coal seam, which causes instability such as fracture of abutment coal pillars and roof, and roof slippage. When the working face causes the overlying pillars, the massive collapse of the main roof occurs easily. Dynamic disturbances often result in bursting, crushing, and damage to the support. In the area of superimposed static load, the critical stress of rockburst may be exceeded to induce the rockburst. 


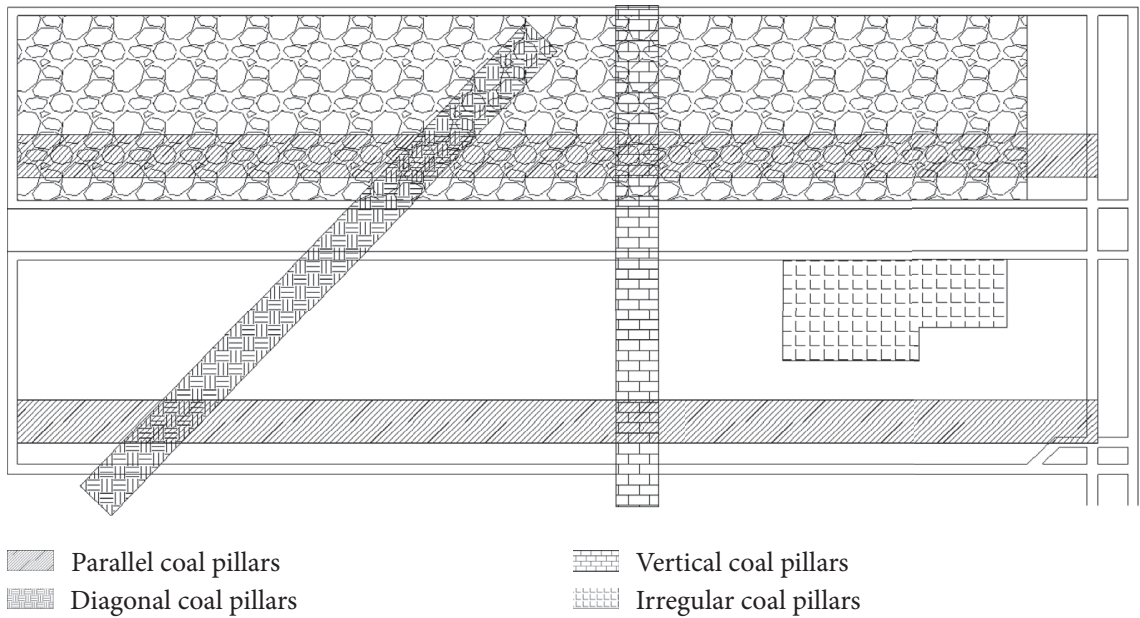

FIGURE 1: Spatial positional relationship diagram of overlying coal pillars and the lower working face.

By summarizing the law of strata behaviors caused by different types of coal pillars, it is found that the mechanism of strata behaviors in the close-distance multiseam is more complicated than that of single-coal seam mining. Moreover, compared with single-coal seam mining, localized static load concentration areas are more common under shallow mining conditions in the close-distance multiseam coal pillars. Repeated mining of multiple coal seams could cause new characteristics of overburden roof migration with a high degree of uncertainty, which increases the difficulty of detecting dangerous zones with strong strata behaviors in the lower coal seams and increases the potential dangers for safe and efficient production. Therefore, based on the classification of close-distance multiseam coal pillars and the characteristics of strong strata behaviors, the mechanism of strong strata behaviors under the conditions was studied, which provides theoretical support for the detection of strata behaviors occurrence.

\section{Main Contributing Factors of Strata Behaviors in the Close-Distance Multiseam Coal Pillar Mining}

The mechanism of strata behaviors in the close-distance multiseam coal pillar mining was studied from the perspectives of static load concentration and dynamic disturbance. The diagonal coal pillars in Xinzhouyao coal mine was taken as an example, and the characteristics of strata behaviors under the effect of various overlying coal pillars were considered. A mechanical model under the effect of overlying coal pillars was established to study the generation and mechanism of dynamic and static load source.

3.1. Static Load Concentration. The section is extracted from the direction perpendicular to the strike of the working face, which is used to study the effect of the overlying coal pillar, the lateral abutment pressure, and the gravity stress of coal and rock on the local static load concentration. The mechanical model of the working face under the overlying coal pillar is established as shown in Figure 2.
3.1.1. Stress Calculation and Stress Transfer of Overlying Coal Seam. The load on the overlying pillars is the superposition of the gravity of overlying strata and the lateral abutment pressure caused by the overhanging roof of goaf. After the overlying coal seam is mined, the load on goaf and pillars tends to distribute evenly after a long time of rebalancing of coal and rock structure. Among them, the load per unit length of the coal pillar can be estimated according to the load estimation model of the coal pillar in Figure 3 [35].

Assuming that the width of goaf on both sides of coal pillar is different, the average load on coal pillars is as follows:

$$
\bar{\sigma}_{\mathrm{M}}=\left[\left(B_{2}+\frac{D_{1}+D_{2}}{2}\right) H-\frac{D_{1}^{2}+D_{2}^{2}}{8} \cot \alpha\right] \frac{\gamma}{B_{2}},
$$

where $D_{1}$ and $D_{2}$ are the width of goaf on both sides of coal pillar, $\mathrm{m} ; \bar{\sigma}_{M}$ is average stress of coal pillar, MPa; $B_{1}$ and $B_{2}$ are the width of coal pillar, $\mathrm{m} ; H$ is the depth of coal seam, $\mathrm{m}$; and $\alpha$ is roof caving angle.

The gravity stress of overlying strata of coal seam minus the load of coal pillars is the load of goafs; then the average load of goafs is as follows:

$$
\bar{\sigma}_{\mathrm{K}}=\frac{2\left[\gamma H\left(B_{2}+\left(\left(D_{1}+D_{2}\right) / 2\right)\right)-\bar{\sigma}_{M} B_{2}\right]}{D_{1}+D_{2}} .
$$

Taking the $\mathrm{AB}$ segment pillar shown in Figure 2 as an example, the stress transferred from the overlying pillar and the goafs to $\mathrm{M}$ point is calculated. The coordinates of $\mathrm{A}, \mathrm{B}$, and $M$ point are $\left(x_{A}, y_{A}\right),\left(x_{B}, y_{B}\right)$, and $(x, y)$, respectively. The infinitesimal element length $d \xi$ is taken at the distance of $\xi$ from the coordinate origin in the $\mathrm{AB}$ segment. According to elastic mechanics [36], the stress caused by the element at $M$ point is as follows:

$$
d \sigma_{y}=\frac{2 \bar{\sigma}_{3} \mathrm{~d} \xi}{\pi} \frac{y^{3}}{\left[y^{2}+(x-\xi)^{2}\right]^{2}} .
$$

The vertical stress transferred from the coal pillar in the $\mathrm{AB}$ section to the $\mathrm{M}$ point is obtained by accumulating the stress of each element in the $\mathrm{AB}$ section. 


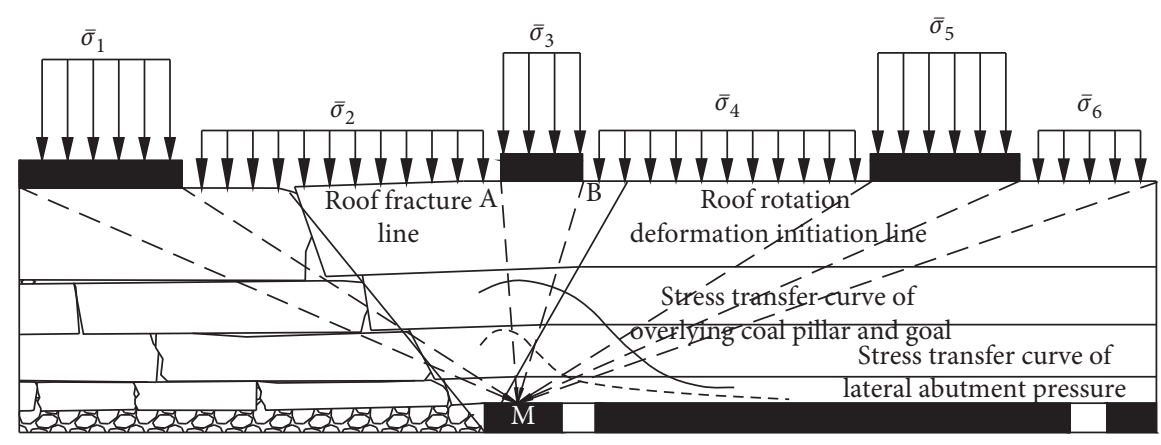

FIGURE 2: Stress model of working face under overlying coal pillar.

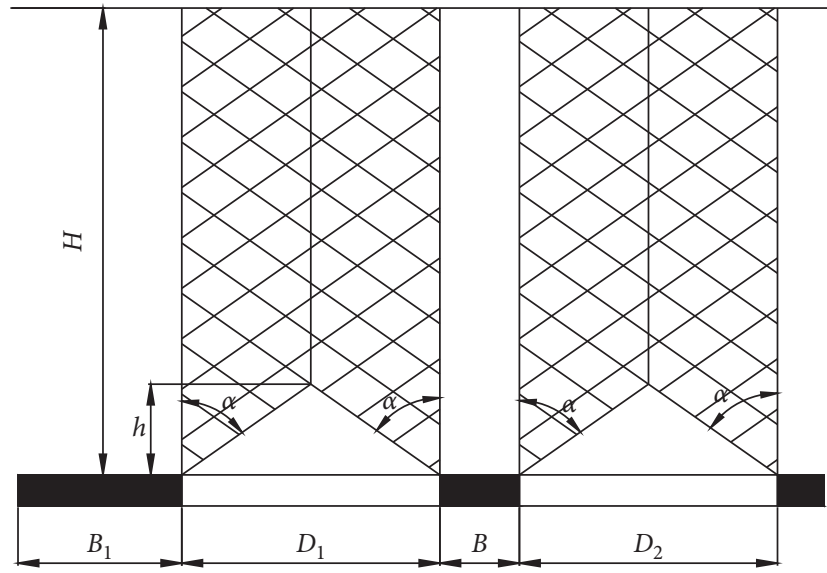

Figure 3: Estimation model of overlying coal seam stress.

$$
\sigma_{3}=-\frac{\overline{\sigma_{3}}}{\pi}\left[\arctan \frac{x-x_{B}}{y}-\arctan \frac{x-x_{A}}{y}+\frac{y\left(x-x_{B}\right)}{y^{2}+\left(x-x_{B}\right)^{2}}-\frac{y\left(x-x_{A}\right)}{y^{2}+\left(x-x_{A}\right)^{2}}\right] .
$$

The stress of the overlying coal pillars and goafs transferring to $\mathrm{M}$ point within the influence range of the lower section coal pillar is calculated according to formula (5), and the stress value of the overlying coal pillars and goafs transferring to the lower coal pillar can be obtained.

$$
\sigma_{\mathrm{I}}=\sum_{1}^{\mathrm{n}} \sigma_{n}
$$

3.1.2. Calculation of Lateral Abutment Pressure. The lateral abutment pressure $\sigma_{\text {II }}$ consists of the gravity stress $\sigma_{\gamma}$ of the overlying strata on the side of the coal body and the additional stress increment $\sigma_{\mathrm{c}}$ transferred from the cantilever roof of gob-side roadway; that is,

$$
\sigma_{\mathrm{II}}=\sigma_{\gamma}+\sigma_{\mathrm{c}}=\gamma h+\sum \Delta \sigma_{i}
$$

where $\Delta \sigma_{\mathrm{i}}(i=1 \sim m)$ is the $i$-th increment of additional stress transferred from cantilever block along the goaf to the lateral coal, $m$ is the number of roof cantilever blocks between lower coal seam and overlying coal seam, and $h$ is the interval between the upper and lower coal seams.

Assuming the cantilever block as an elastic body, the additional loads generated are distributed uniformly on the surface of the bearing rock strata. Only the strata between the two coal seams are considered and the interval between them is small, the force of the cantilever block here is calculated according to the structure without articulation. The additional load generated by the cantilever block is $\Delta q_{i}=Q_{i} / L_{i}$, where $Q_{i}$ is the sum of the weight of the cantilever block in the $i$-th layer and the weight of the cantilever block between the roof of the $i$-th layer and the overlying coal seam. $L_{i}$ is the vertical distance from the cantilever block rotation deformation initiation point in $i$-th layer to the coal wall [37], as shown in Figure 4.

Taking the second layer of cantilever block as an example, the stress transferred to $M$ point from the additional load of the single layer cantilever block is calculated. The coordinates of $\mathrm{C}$ and $\mathrm{D}$ at the intersection of the coal wall 


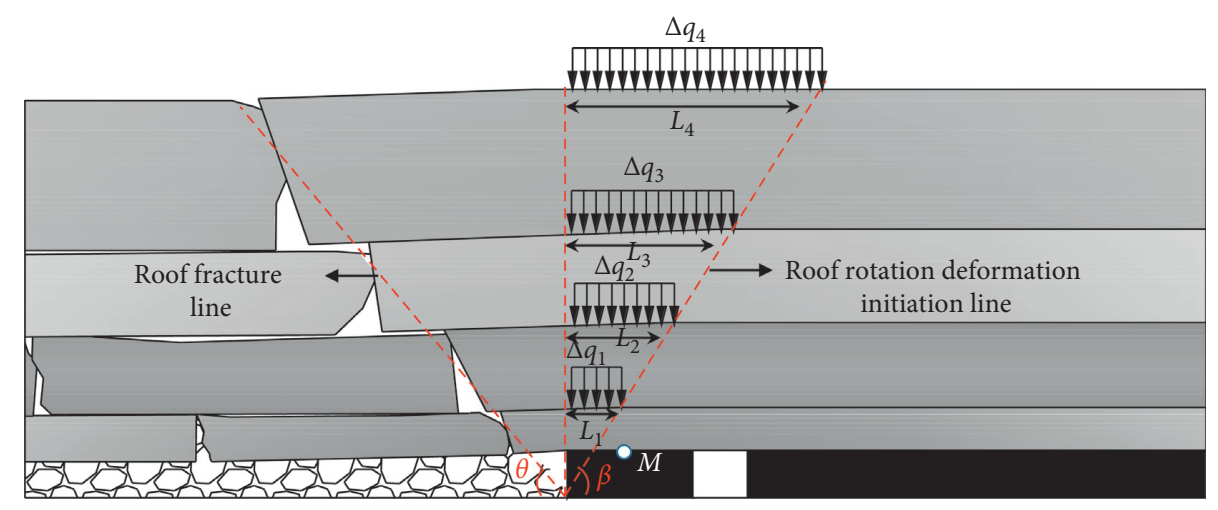

Figure 4: Additional load distribution of the cantilever block along the goaf side.

extension line, the starting line of rotation, and the upper boundary of the second layer cantilever block are $\left(\mathrm{x}_{\mathrm{C}}, \mathrm{y}_{\mathrm{C}}\right)$ and $\left(\mathrm{x}_{\mathrm{D}}, \mathrm{y}_{\mathrm{D}}\right)$, respectively. The length of microelement is taken at the distance from the origin of coordinates on CD segment, and the stress caused by the microelement at Point $\mathrm{M}$ is

$$
\mathrm{d} \sigma_{y}=\frac{\Delta q_{2} \mathrm{~d} \xi}{\pi} \frac{y^{3}}{\left[y^{2}+(x-\xi)^{2}\right]^{2}}
$$

By integrating the stress of $\mathrm{CD}$ section, the stress transferred to $M$ point by the additional load of the cantilever block in the second layer can be obtained as follows:

$$
\Delta \sigma_{2}=-\frac{\Delta q_{2}}{\pi}\left[\arctan \frac{x-x_{D}}{y}-\arctan \frac{x-x_{C}}{y}+\frac{y\left(x-x_{D}\right)}{y^{2}+\left(x-x_{D}\right)^{2}}-\frac{y\left(x-x_{C}\right)}{y^{2}+\left(x-x_{C}\right)^{2}}\right] .
$$

According to formula (8), the stress $\Delta \sigma_{i}$ of cantilever block in each layer at $M$ point can be calculated, and the lateral abutment pressure at $M$ point can be obtained by bringing the calculation results into formula (6).

As shown in Figure 5(a), this paper takes the 8308 working face of Xinzhouyao mine as an example to calculate the stress value of each static load source on the section I-I along the strike of the vertical working face. The width of the overlying coal pillars in the upper coal seam is $37 \mathrm{~m}, 51 \mathrm{~m}$, and $44 \mathrm{~m}$ from left to right, and the width of the goaf is $58 \mathrm{~m}$ and $100 \mathrm{~m}$. The width of the upper coal pillar and the goaf are calculated according to formulas (1) and (2). The coal pillars and goafs bear stress, the roof caving angle $\alpha=85^{\circ}$, the upper coal burial depth is $272 \mathrm{~m}$, $\gamma=\mathrm{KN} / \mathrm{m}^{3}$, the turning initiation angle $\beta=75^{\circ}$, the upper and lower coal seam spacing is $h=30 \mathrm{~m}$, and the above parameters are compared with the upper coal pillar and mining. The stress carried by the goaf is introduced into formulas (4) and (5), and the stress value transmitted by the overlying pillars and the goaf to the lower coal can be obtained; the thickness of the lower coal roof is $3 \mathrm{~m}, 4 \mathrm{~m}$, $6 \mathrm{~m}$, and $17 \mathrm{~m}$ from bottom to top, and the above parameters can be taken into formulas (6) and (8) to obtain the lateral support pressure generated on one side of the goaf and integrate the overlying coal pillars and the stress transferred from the goaf to the lower coal value and the value of the lateral support pressure generated on one side of the goaf; the stress of each static load source acting on the section I-I of the lower coal seam can be obtained, as shown in Figure 6.
The calculation indicated that the peak stress was 1.8 times of the original gravity stress, and the upper side coal pillar transmitted $78.3 \%$ of the stress. The peak stress generated by the lateral support pressure was $1.93 \mathrm{MPa}$, which is located at $3 \mathrm{~m}$ to the boundary of the section coal pillar, accounting for $16 \%$ of the total vertical stress at that position. Therefore, the main sources of static load concentration in the close-distance multiseam coal mining are the stress transmitted by overlying coal pillars and the lateral bearing pressure.

3.2. Dynamic Disturbance of Multiseam Coal Mining. The source of dynamic load in coal mining is the dynamic response of coal and rock mass caused by mining activities. Under the condition of close-distance multiseam coal pillar mining, dynamic load is not only generated by the roof breaking of this coal seam but also by the secondary roof breaking of the coal pillars and roof.

According to the elastic wave propagation theory, the additional stress caused by the vibration stress wave propagating from the seismic source to the surrounding coal and rock mass is

$$
\sigma_{d}=\sigma_{0} e^{-\lambda L}
$$

where $\sigma_{d}, \lambda$, and $L$ are the initial intensity of the stress wave generated by the vibration, the energy attenuation index of the vibration wave, and the distance from the source to the location of the excavation space, respectively. 


\begin{tabular}{|c|c|c|c|}
\hline Column & Lithology & $\operatorname{Depth}(\mathrm{m})$ & Thickness(m) \\
\hline & Sandstone & 266.70 & 13.81 \\
\hline & Sandy shale & 276.23 & 2.60 \\
\hline & $\begin{array}{c}11-2 \# \\
\text { coal seam }\end{array}$ & 278.83 & 4.48 \\
\hline & Sandstone & 283.31 & 8.80 \\
\hline & Shale & 292.11 & 10.05 \\
\hline & $\begin{array}{l}\text { Medium } \\
\text { sandstone }\end{array}$ & 302.16 & 6.72 \\
\hline & Sandy shale & 308.88 & 4.20 \\
\hline & $\begin{array}{c}14-2 \# \\
\text { coal seam }\end{array}$ & 313.08 & 3.30 \\
\hline & Sandy shale & 316.38 & 4.35 \\
\hline & $\begin{array}{c}\text { Medium } \\
\text { sandstone }\end{array}$ & 320.73 & 5.68 \\
\hline & $\begin{array}{c}15 \# \\
\text { coal seam }\end{array}$ & 326.41 & 6.09 \\
\hline & Sandstone & 332.50 & 1.63 \\
\hline & Sandy shale & 334.13 & 5.15 \\
\hline
\end{tabular}

(a)

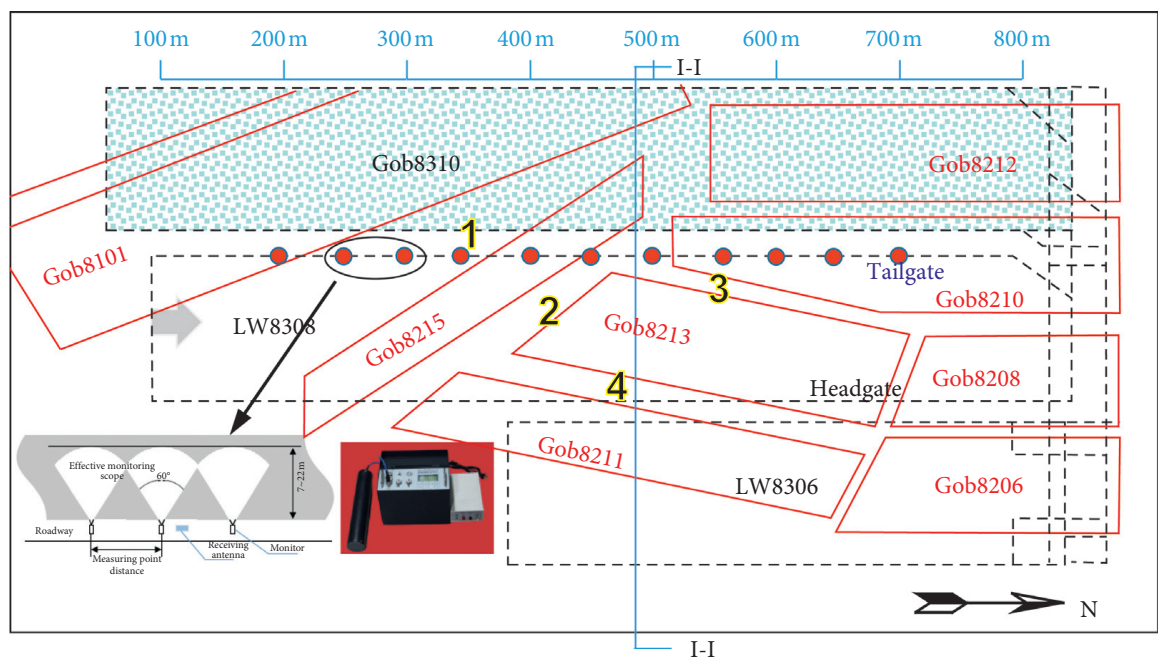

- The 11-2 coal seam's goaf

- - The $14-3^{\#}$ coal seam's coalface

(b)

FIgUre 5: (a) Borehole column map; (b) Comparison map of 8308 working face and 11-2 coal seam goaf.

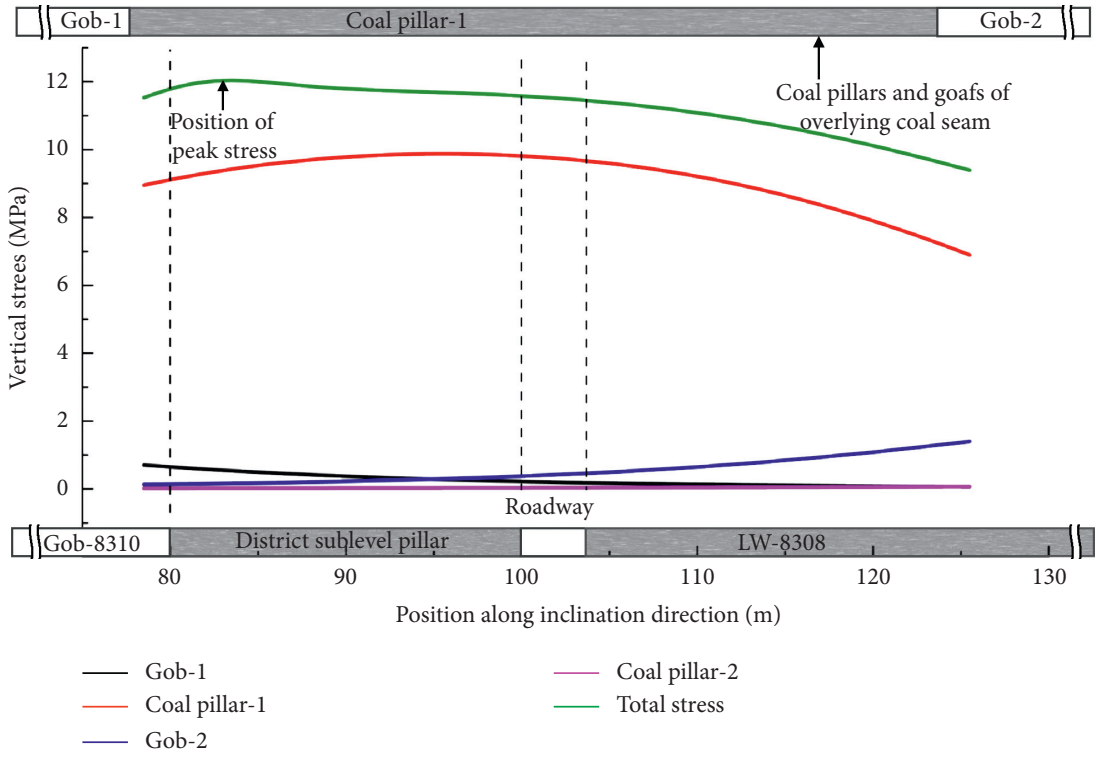

FIgURE 6: Stress distribution of overlaying coal pillars in the upper layer, goaf, and lateral supports.

Under the condition of the close-distance multiseam coal pillar mining, the roof fracture in the upper goaf is significant, wherein the dynamic disturbance caused by repeated mining roof fracture and migration is relatively small. The integrity of the roof supported by the overlying coal pillar is optimal, which is also affected by the stress concentration. When the stable structure is broken during repeated mining, the fractured rock block of the remaining coal pillar roof inevitably causes further rotary movement. When this kind of structure cannot maintain its stability, it will produce high-energy dynamic disturbance to the working face of the lower coal seam.

According to the dynamic and static load superposition principle [38], in the case of the close-distance multiseam coal pillar mining, the mining area under the overlying coal pillar is more likely to have strata behaviors, as shown in Figure 7.

$$
\sigma_{j}+\sigma_{d}=\sigma_{j}+\sigma_{0} e^{-\lambda L} \geq \sigma_{\min }
$$

where $\sigma_{j}$ is the static load stress caused by multiple force sources and $\sigma_{\min }$ is the critical stress when rockburst occurs.

The mechanistic study indicated that the main contributing factors of strata behaviors are the static stress concentration caused by the overlying coal pillar and the dynamic disturbance caused by fracturing and sliding of the overlying coal pillar and roof under the influence of mining. The established mechanical model can quantify the static load stress concentration caused by overlying coal pillars. The 


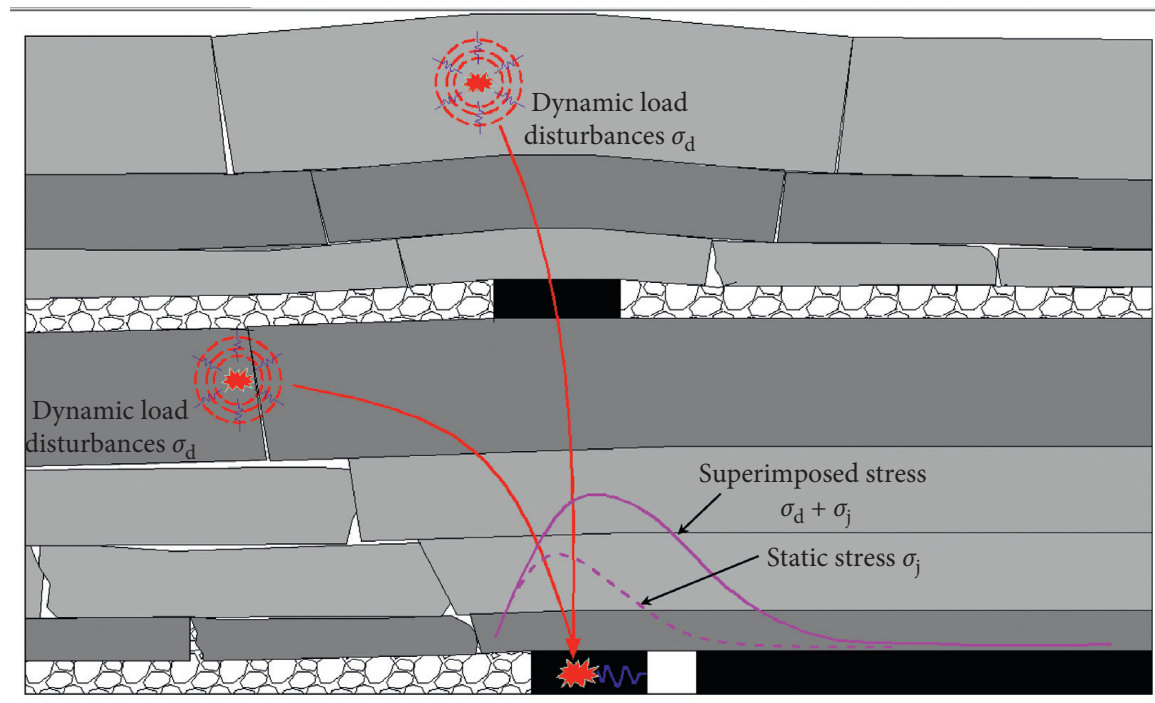

Figure 7: Dynamic disturbance diagram of mining retained pillar in close multiseam.

calculation results showed that the stress concentration caused by coal pillars was related to the layer spacing and the horizontal distance from the coal pillars. According to the analysis of the coal pillars and roof structure of the upper coal seam, it was concluded that high-energy quakes were mainly concentrated near the overlying coal pillars, and high-energy quakes were unlikely to occur in the top and bottom floors of the upper goaf. According to the propagation law of stress wave generated by vibration, the dynamic disturbance is more obvious in the area closer to the overlying coal pillar.

The mechanistic study plays a guiding role in the identification of anomalous areas with strong strata behaviors. However, there are differences between theoretical research and actual stress distribution and surrounding rock migration. Taking Xinzhouyao mine as an example, the mining of multiple coal seams with coal pillars at close distances is used to verify the mechanism of mineral pressure manifestation under this condition through field multiparameter monitoring methods.

\section{Engineering Validation}

4.1. Engineering Background. Xinzhouyao coal mine is located in Datong Mining Area, Shanxi Province. It mainly mines Jurassic coal seams, which are 9\#, 11\#, and 14\# coal seams from top to bottom, respectively. The seam spacing is mostly $8 \sim 30 \mathrm{~m}$, which is a typical short-distance multiseam coal pillar mining mine. Xinzhouyao coal mine 11-2\# and 143 \# coal seams overlap in the East 2 and East 3 panels. A large number of irregular coal pillars were reserved during the 112\# coal seam mining process, which causes severe abnormal strata behaviors in 14-3\# coal seam. In particular, during the mining of working faces 8112,8310 , and 8308 in 14-3\# coal seam, the occurrence of strong strata behaviors is frequent, which causes significant damage to the roadway and seriously affects safety and efficient mining on the working face.

The 8308 working face is located in the 14-3\# coal seam in the east third panel of Xinzhouyao coal mine with a nearly horizontal coal seam inclination angle. The working face is buried at a depth of about $285 \mathrm{~m}$, where the top and bottom floors are all hard rocks. The histogram of the borehole is shown in Figure 5(a). The 8308 working face consists of 5308 track lane and 2308 belt lane $880 \mathrm{~m}$ long and $131 \mathrm{~m}$ wide. The west side of 8308 working face is the 8310 goaf, while the east side is the 8306 working face to be mined, in which the abutment pillar is $20 \mathrm{~m}$ wide. At the distance of about $30 \mathrm{~m}$ to the 11-2\# coal seam, the 11-2\# coal seam was mined during the mining period of 8308 working face. The 8308 working face is mainly affected by the overlying coal pillars 1 to 4 . The layout of the working face and the distribution of the overlying coal pillars are shown in Figure 5(b).

In tailgate, EMR monitoring point (MP) is set every $50 \mathrm{~m}$ away from the open-off cut, which are Mp-200, Mp-250, ..., $\mathrm{Mp}-700$. The layout of EMR monitoring position is shown in Figure 5(b). Microseismic system of Xinzhouyao coal mine is an SOS system made by Polish General Institute of Mining Research. The layout of MS equipment and probe is shown in Figure 8.

4.2. Reginal-Localized Static Load. In areas with high stress and high concentration, compared with other areas, positive anomalies of $\mathrm{P}$-wave velocity would occur. According to this principle, the stress anomaly distribution area can be detected by the seismic computed tomography CT. Table 1 shows the relationship between positive wave velocity anomaly coefficients, stress concentration, and strata behavior anomalies. The anomalous values are calculated from the following formula (10) [39].

$$
A_{\mathrm{n}}=\frac{V_{\mathrm{p}}-\stackrel{\mathrm{pa}}{\mathrm{pa}}}{V},
$$

where $V_{\mathrm{p}}$ is the $\mathrm{P}$-wave velocity value at certain point in the inversion area and ${ }_{V}^{\mathrm{pa}}$ is the average value of the model wave velocity. 


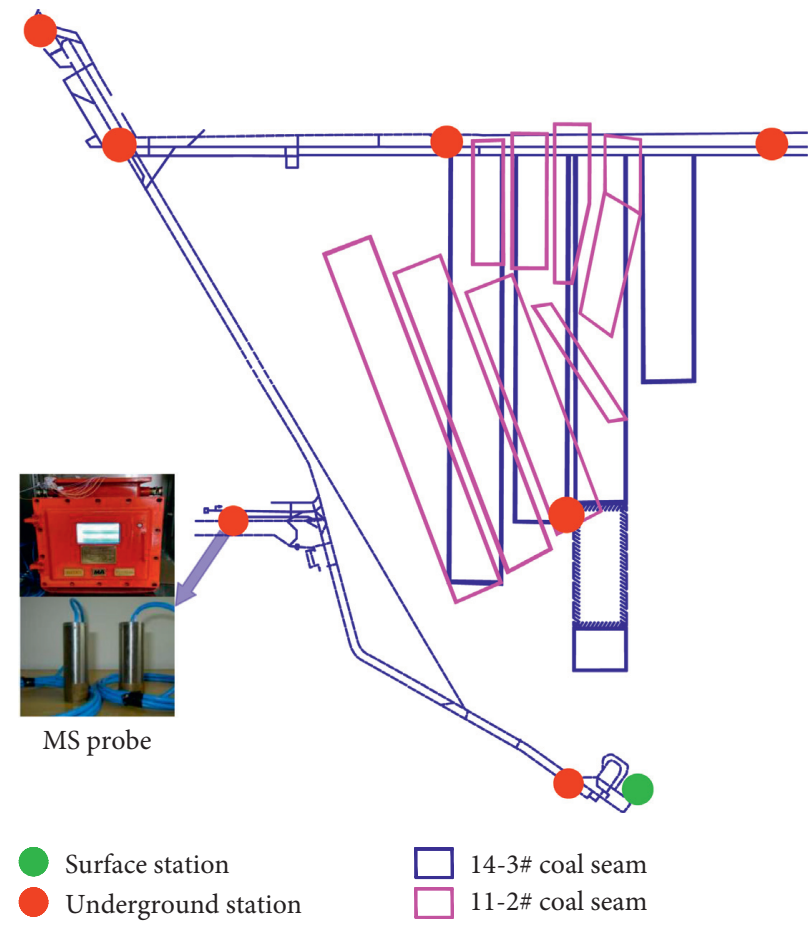

FIGURE 8: Schematic diagram of Microseismic equipment and probe layout.

TABLE 1: Stratified statistical table of microseismic events.

\begin{tabular}{lccc}
\hline & & Layers & \\
Energy & $14-3 \#$ coal seam floor & 14-3\# coal seam roof & $11-2 \#$ coal seam roof \\
\hline $1 \times 10^{4} \mathrm{~J} \sim 1 \times 10^{5} \mathrm{~J}$ & 60 & 147 & 130 \\
$1 \times 10^{5} \mathrm{~J} \sim 1 \times 10^{6} \mathrm{~J}$ & 2 & 17 & 24 \\
\hline
\end{tabular}

Based on the MS monitoring data during the mining period of LW8308, the passive velocity tomography of LW8308 is carried out. The 3D model of passive velocity tomography is shown in Figure 9. The isoline cloud map of wave velocity anomaly coefficients of $+896 \mathrm{~m}$ horizontal slice of the 8308 working face was selected as the detection result of dangerous area. The inversion result is shown in Figure 10.

It can be seen from Figure 10 that the high-wave velocity anomaly zone was mainly distributed under the overlapping area superposed with overlying coal pillars, lateral abutment pressure, and advanced bearing pressure. In the mining process, the high-wave velocity anomaly zone was dynamically changing. As shown in Figure 10(a), the high-wave velocity anomaly zone was located under the two diagonal coal pillars during the mining phase, the section $100 \mathrm{~m}$ in front of the working face near the coal pillars $A_{n}>0.2 \%$. As shown in Figure 10(b), during the mining phase, the highwave velocity anomaly zone was mainly located below the overlying diagonal coal pillars in front of the working face, and the maximum value of the positive wave velocity anomaly $A_{n}$ appeared at the corners of the overlying coal pillars 2 and 3 with $A_{n}>0.2 \%$. Affected by the overlying coal pillar and lateral abutment pressure, the wave velocity anomaly coefficient in the high-wave velocity anomaly zone was about two times that of other regions. According to the calculated stress at section I-I in Figure 5(b), the peak stress reached 1.8 times the original gravity stress, which indicated that the seismic computed tomography CT detection results of the shock wave were highly consistent with the theoretical calculation results.

According to the study of the characteristics of EMR signals during the loading of coal samples in Xinzhouyao coal mine, it was found that the EMR signal and number of pulses are positively correlated with stress. Combined with the previous EMR field monitoring results, critical values for EMR detection of danger zone were determined. When the EMR intensity value was greater than $100 \mathrm{mv}$ and the number of pulses was larger than $700 \mathrm{~Hz}$, the stress concentration was considered to be high. The EMR data measured by the EMR instrument (KBD5) in the roadways near gob during the mining of the 8308 working face was analyzed. The results are shown in Figure 11.

It can be seen from Figure 10 that the peak values of intensity and pulse number in the EMR monitoring data were mainly located in the range of 50 150 meters ahead of the working face. The monitoring results on December 18, 2017, showed that the intensity values of the coal wall side near $300 \mathrm{~m}$ and $700 \mathrm{~m}$ from the cut-hole were more than $200 \mathrm{mv}$, and the number of pulses on the coal wall side near 


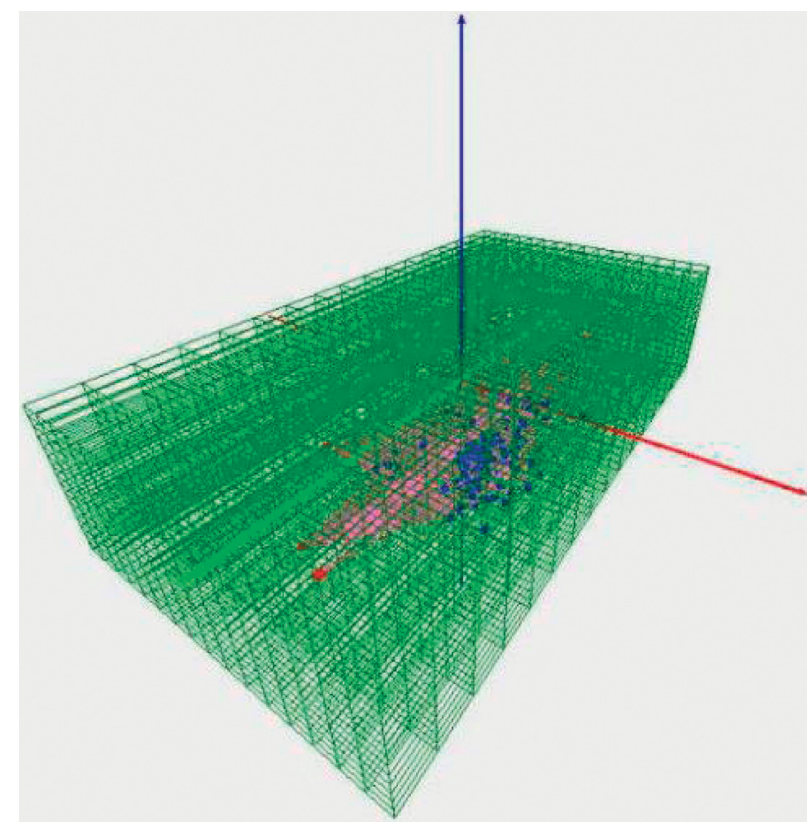

FIGURE 9: Model diagram of passive velocity tomography of LW8308.

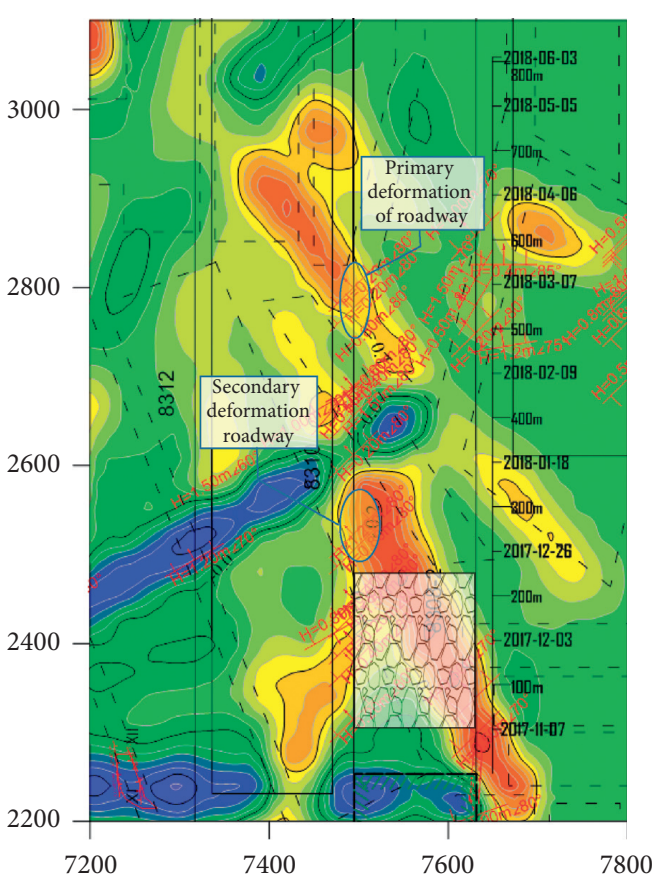

(a)

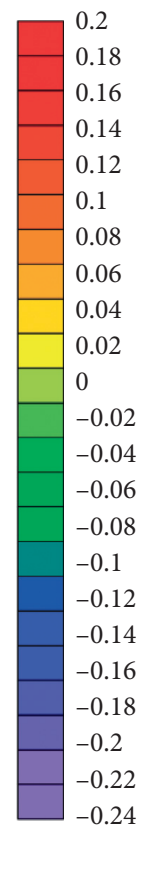

$-0.12$

$-0.14$ 16 22 24 7200 (1)

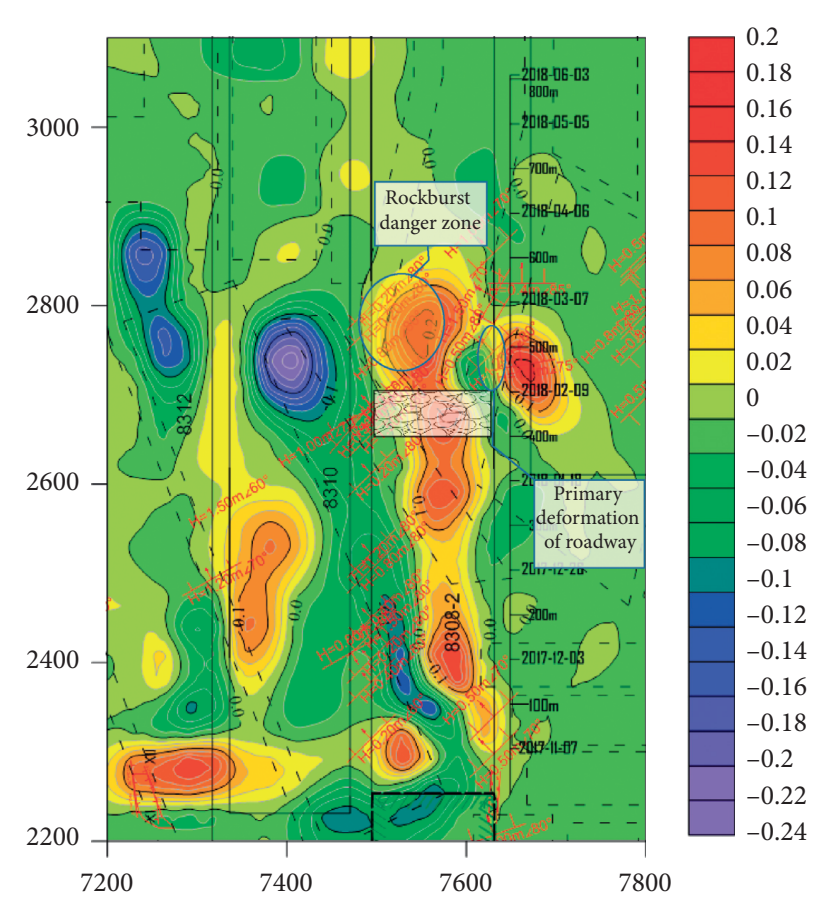

(b)

FIGURE 10: Distribution of abnormal coefficients of wave velocity in different mining times: (a) 2017-11-7 to 2017-12-20; (b) 2018-1-30 to 2018-2-10.

$700 \mathrm{~m}$ from the cut-hole exceeded $19300 \mathrm{~Hz}$. Based on the monitoring results on December 26, 2017, it can be seen that the EMR intensity values all exceeded $100 \mathrm{mv}$ near the working surface. The dangerous areas detected by EMR were located under the overlying coal pillars 1, 2, and 3, which belong to the area that is comprehensively affected by the overlying pillars and lateral abutment pressure.
Based on the results of the regional seismic computed tomography CT and localized EMR detection, four dangerous zones with strata behaviors in the roadway were successfully detected by the regional-localized static load approach, which were located in the roadways near gob with distances of $250-300 \mathrm{~m}$ and $600-700 \mathrm{~m}$ to the cuthole, as well as Lane 2308 near $500 \mathrm{~m}$ from the cut-hole. 


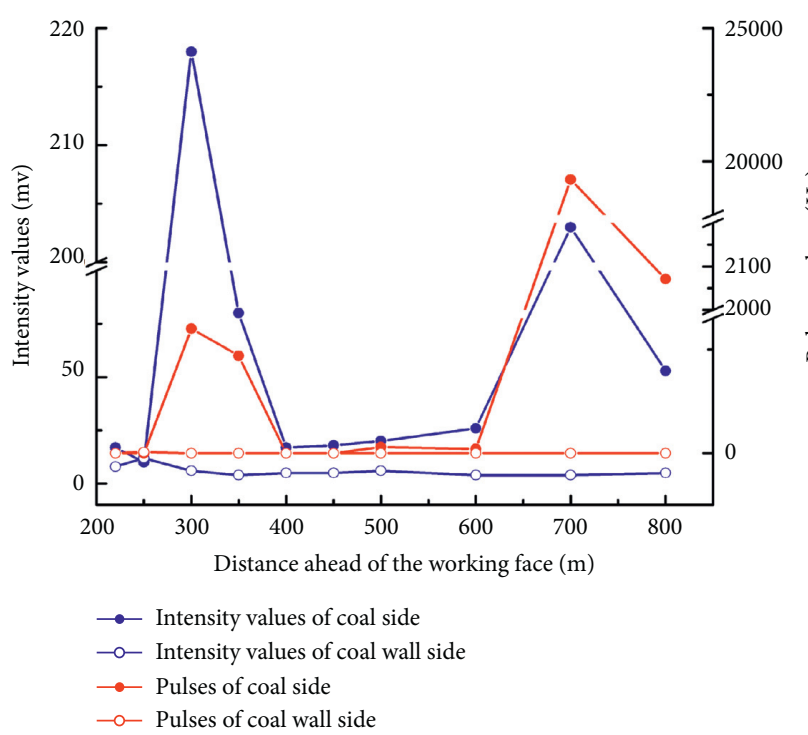

(a)

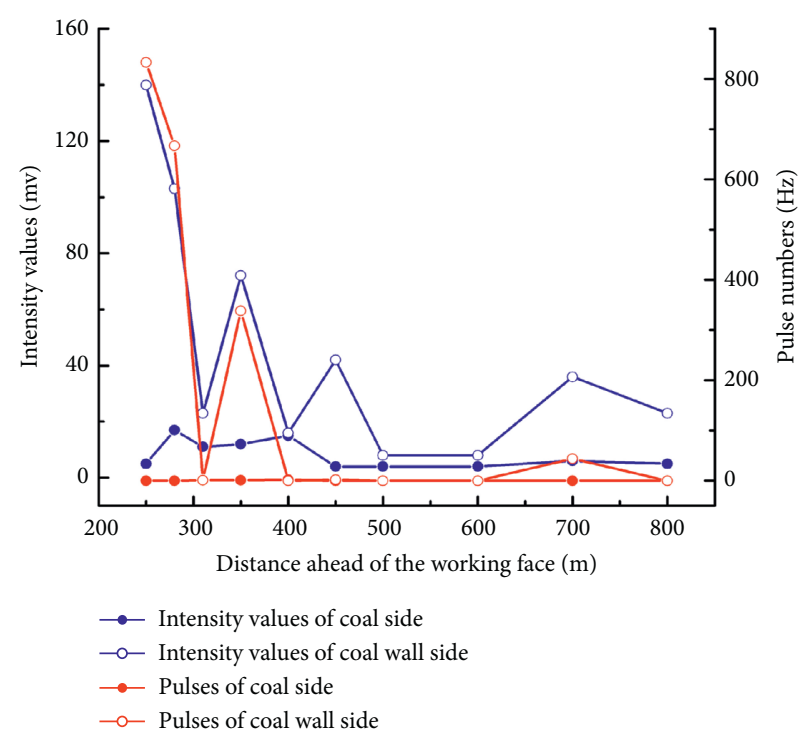

(b)

FIGURE 11: Monitoring results of EMR in 5308 roadway: (a) 2017.12.18; (b) 2017.12.26.

Among them, floor heave of the roadway and inward shifts of two roadway sides occurred in the roadways near gob in the range of $250-300 \mathrm{~m}$ and $600-700 \mathrm{~m}$ from the cut-out during the mining process, which is affected by the static load stress of overlying coal pillars 1,2 , and 3 . The stress calculation results of section I-I in Figure 7(b) showed that the stress concentration factor of the working face directly above the coal pillar could reach about 1.8 at a spacing distance of $30 \mathrm{~m}$ between the upper and lower coal seams. These results are in good agreement with the results of seismic computed tomography CT, EMR detection, and on-site strata behaviors.

4.3. Regional Dynamic Load Characteristics. Figure 12 is a time series of daily accumulated energy and frequency of microseisms during the entire mining period of the 8308 working face. The mining position in Figure 12 corresponded to the coal and rock structure of the working face. It can be seen that, on December 8, 2017, the working face was advancing through the intersection of the upper section coal pillar and overlying coal pillar 1, in which the frequency of the energy of the microseisms began to increase. During the period from December 8, 2017, to February 28, 2018, the cumulative frequency of the microseismic events per day was mostly above 10 with daily cumulative energy above $1 \times 10^{4} \mathrm{~J}$. This period corresponded to the shift of the roadway sides at the mining location. The maximum shift of the two roadway sides reached $2 \mathrm{~m}$. After March 15, 2018, high-frequency microseismic phenomena occurred in the overlying areas of small coal pillars and pressure relief areas, but the microseismic energy was generally low without strong strata behaviors in the roadway.

Figure 13 is the source location of microseismic events during the entire mining period of the 8308 working face. The original microseismic data $\left(>1 \times 10^{4} \mathrm{~J}\right)$ during the entire mining period of the 8308 were loacted in different orders of magnitude for spatial location.

It can be seen from the location map of microseismic events in Figure 13(a) that the distribution of microseismic events was closely related to the overlying coal pillars. From the perspective of spatial distribution, the diagonal intersection between the overlying coal pillars and section coal pillars is more likely to cause microseismic events with energy greater than $10^{5} \mathrm{~J}$. Microseismic events with energy greater than $10^{6} \mathrm{~J}$ were all located in the upper coal seam. According to the spatial distribution, it can be concluded that the overlying coal pillars and their roofs were unstable.

Vertical section location map of the microseismic events in Figure 13(b) indicated that the microseismic events were mainly concentrated on the 11-3\# coal seam roof when the working face was crossing the two large overlying pillars 1 and 2. After that, microseismic events were mainly concentrated on the roof of the 14-2\# coal seam, which is closely related to the roof fracture of the large coal pillar from the 11-3\# coal seam. Affected by the secondary fracture of the large pillar and the roof of the overburdened 11-3\# coal seam, secondary damage occurred in the roadway after the support and expansion measures were taken. The monitoring of the microseismic space location and the observation of the degree of influence of strata behaviors on the roadway confirm the above discussion of the distribution of high-energy microseismic events and their impacts. The high-energy microseismic events are mainly concentrated near the overlying coal pillars while goaf in the upper layer is unlikely to have high-energy mine earthquakes. According to the propagation law of stress wave generated by vibration, the area nearer to the overlying coal pillar is more affected by dynamic load.

For better quantitative analysis of the relationship between dynamic disturbance and overlying pillars, different orders of magnitude of microseismic events that occurred in 


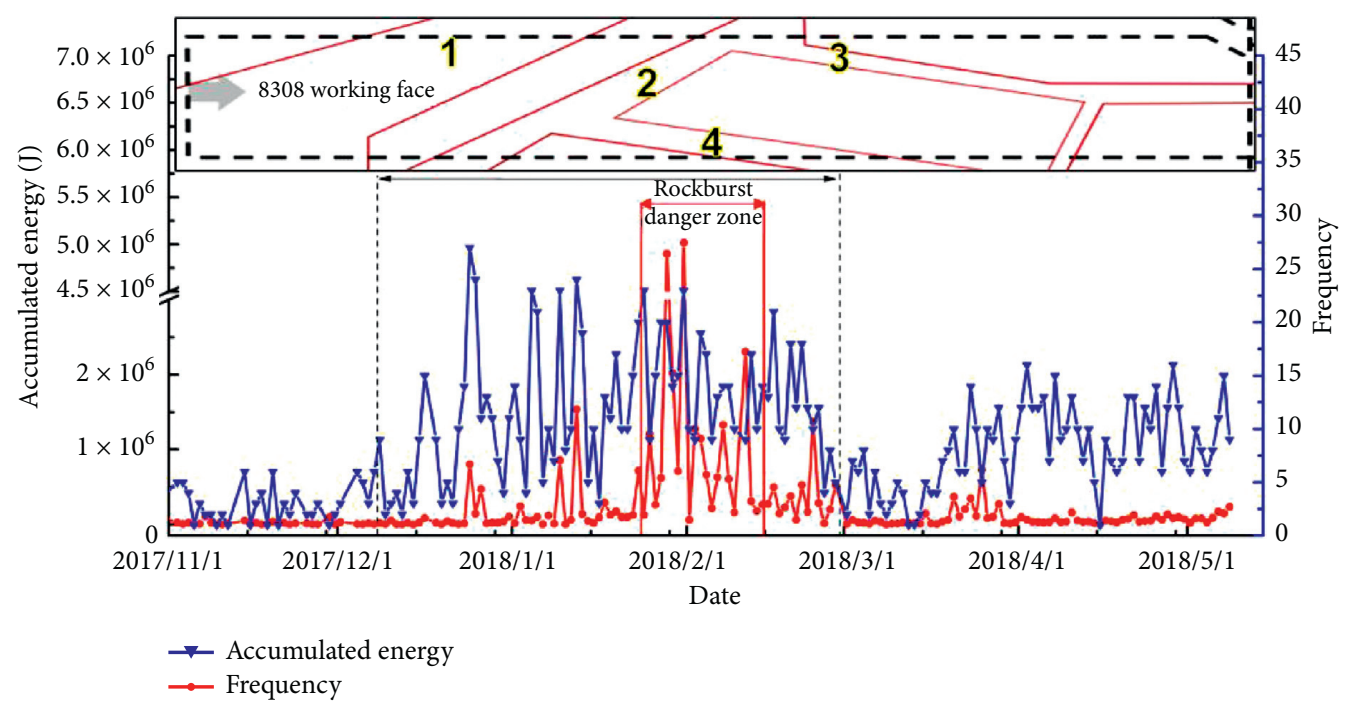

FIGURE 12: Time series variation of microseismic energy frequency.
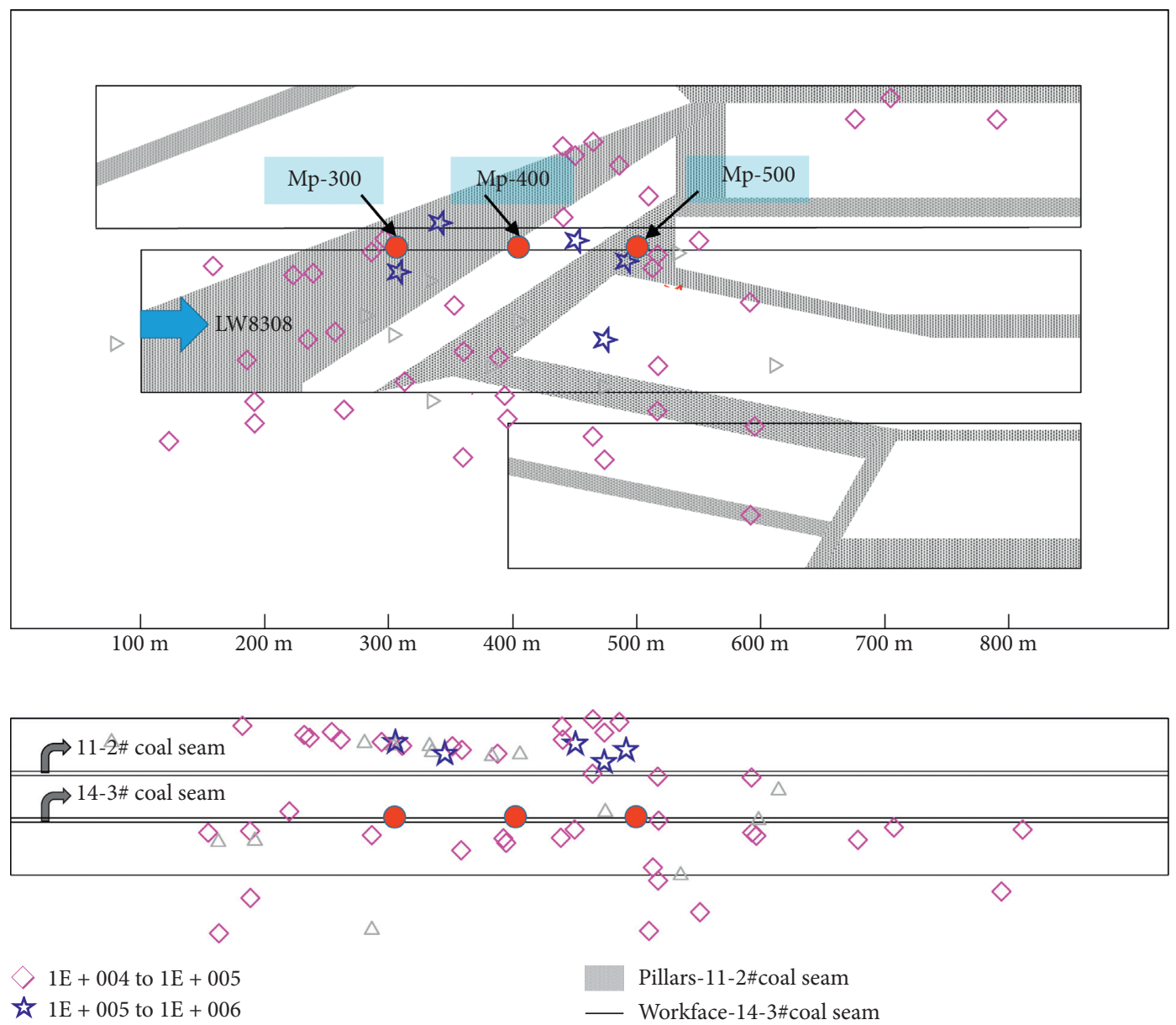

FIGURE 13: (a) Location map of the horizontal profile of microseismic events. (b) Location map of microseismic events along strike profile.

different layers of coal seam were counted (shown in Table 1). The spatial locational relationship between microseismic events and overlying pillars is shown as Figure 13. High-energy events (energy is greater than $10^{4} \mathrm{~J}$ ) distributed in the 14-3\# coal seam floor, 14-3\# coal seam roof, and 11-2\# coal seam roof account for $16 \%, 43 \%$, and $41 \%$ of total events, respectively, while high-energy events ranging from $1 \times 10^{5} \mathrm{~J}$ to $1 \times 10^{6} \mathrm{~J}$ account for $5 \%, 40 \%$, and $55 \%$ in the three layers, and the ones surpass $1 \times 10^{6} \mathrm{~J}$ account for $17 \%$, $17 \%$, and $66 \%$. It can be concluded that microseismic events 
are mainly distributed in 14-3\# coal seam roof and 11-2\# coal seam roof. Combining location map (shown in Figure 13), it can be obtained that high-energy microseismic events are mainly distributed near the overlying pillars, the higher the energy of the events, the more they are accounted for in the upper coal seams.

Synthesizing the results of reginal-localized static load concentration detection area and reginal temporal-spatial microseismic dynamic load evolution results, it can be found that the detection results of various monitoring devices are highly consistent with the actual locations of strong strata behaviors. Thereinto, theoretical calculation results show that overlying pillars and lateral abutment pressure contribute $78.3 \%$ and $16 \%$ to concentrated stress, respectively. The areas with high abnormal coefficients of wave velocity detected by CT are mainly distributed in areas affected by both lateral abutment pressure and advance abutment pressure under overlying pillars. Besides, the intensity and pulses peak values of EMR monitoring data are mainly distributed under overlying pillars too. Theoretical model calculation results and multiparameter monitoring results point to the same dangerous areas, where actual strata behaviors appeared. Through theoretical analysis of the migration of overlying strata of close-distance multiseam mining, it can be concluded that dynamic disturbances are mainly distributed in the static load concentration areas affected by overlying pillars and they are highly consistent with breakage and slippage of overlying pillars and roof induced by mining process. In-site temporal and spatial seismic monitoring results show that when mining across areas under the bigger overlying pillars, microseismic energy and count begin to rise, and accumulated energy would be over $1 \times 10^{4} \mathrm{~J}$ most of the time. While areas affected by the smaller pillars and pressure relief areas are distributed with high-frequency microseismic, but normally with low energy, thus, there is no appearance of strata behavior in roadway. Spatial statistical analysis of microseismic indicates that high-energy microseismic events are mainly distributed near overly pillars in the upper coal seam. All the results abovementioned verify the conclusion of close-distance multiseam strata behaviors' mechanism in two aspects of multiparameter monitoring results and actual strata behaviors. This method could provide a reference for mining enterprises to quantitative calculation of stress distribution under similar conditions and the identification of the danger zone of strata behaviors.

\section{Conclusion}

(1) According to the positional relationship with the direction of the working face, coal pillars in the closedistance multiseam mining are divided into four categories: parallel coal pillars, diagonal coal pillars, vertical coal pillars, and irregular coal pillars. Based on different classifications and characteristics of the strata behaviors, a mechanical model for the strata behaviors in close-distance multiseam coal pillar mining was established. It was concluded that the main contributing factors for the strata behaviors were static stress concentration caused by overlying coal pillars and dynamic load including mininginduced fracture and slipperiness of pillars and roofs influenced.

(2) According to the calculation results of the mechanical model of Xinzhouyao mine, it can be seen that the coal pillar directly above the roadway is the main factor causing the stress concentration around the roadway in the lower coal seam. At 8308 working section I-I, the peak stress was 1.8 times the original gravity stress, and the coal pillar directly above the working section transmitted $78.3 \%$ of the stress. The peak stress generated by the lateral support pressure accounted for $16 \%$ of the vertical stress at this location.

(3) The results of the multiparameter detection were highly consistent with the actual position where strata behaviors appear. The static stress concentration areas were distributed in the vicinity of the overlying coal pillar, and the stress was even higher under the effect of superimposed lateral abutment pressure and advanced bearing pressure. The overlying pillar roof was well supported by the coal pillars, but under the effect of stress concentration, dynamic energy disturbances are more likely to occur under repeated mining. Since the roof of the upper goaf was fractured sufficiently, the dynamic disturbance caused by the fracturing and migration of the roof on the upper goaf was insignificant when mining the lower coal seam. The on-site multiparameter detection results and actual strata behaviors characteristics confirmed the relevant conclusions of the strata behaviors mechanism of the close-distance multiseam mining. This mechanical model can be used to guide the identification of dangerous strata behaviors in the close-distance multiseam coal pillar mining.

\section{Data Availability}

The data used to support the findings of this study are included within the article.

\section{Conflicts of Interest}

The authors declare that they have no conflicts of interest to this work.

\section{Authors' Contributions}

H. $\mathrm{Mu}$ and Y. Bao contributed equally to this paper.

\section{Acknowledgments}

This work was financially supported by the National Natural Science Foundation of China (Grant nos. 51634001 and 51774023) and Beijing Science and Technology Nova Project (Grant no. xx2018073). The authors would like to express their gratitude to all the agencies for funding this research. 


\section{References}

[1] F. X. Jiang, Y. X. Wang, M. Ling, and Y. L. Yang, "Mechanism of rock burst occurring in protected coal seam induced by coal pillar of protective coal seam," Chinese Journal of Geotechnical Engineering, vol. 39, no. 9, pp. 1689-1696, 2017.

[2] B. Yu, C. Y. Liu, J. X. Yang, and J. R. Liu, "Mechanism of strong pressure reveal under the influence of mining dual system of coal pillar in Datong mining area," Journal of China Coal Society, vol. 39, no. 9, pp. 40-46, 2014.

[3] B. S. Zhang, S. S. Yang, L. X. Kang, and Y. D. Zhai, "Discussion on method for determining reasonable position of roadway for ultra-close multi-seam," Chinese Journal of Rock Mechanics and Engineering, vol. 27, no. 9, pp. 97-101, 2008.

[4] R. W. Hill, "Multi-seam mining on South African collieries," in Proceedings of the 14th International Conference on Ground Control in Mining, pp. 305-311, Morgantown, WV, USA, August 1995.

[5] A. M. Suchowerska, J. P. Carter, and R. S. Merifield, "Horizontal stress under supercritical longwall panels," International Journal of Rock Mechanics and Mining Sciences, vol. 70, pp. 240-251, 2014.

[6] R. Howarth and N. R. Monger, Multi-seam Working. Australian Coal Mining Practice-Monograph 12pp. 376-391, Australasian Institute of Mining and Metallurgy (AusIMM), Carlton, Victoria, Australia, 3rd edition, 2009.

[7] C. Mark, F. E. Chase, and D. M. Pappas, "Analysis of multiple seam stability," in Proceedings of the 26th international conference on ground control in Mining, pp. 22-30, Canonsburg, PA, USA, July 2007.

[8] P. B. CartwrightA, "Review of recent in-situ stress measurements in United Kingdom coal measures strata," in Proceedings of the International Symposium on Rock Stress, pp. 469-474, Kumamoto, Japan, October 1997.

[9] X. Yang, G. Wen, L. Dai, H. Sun, and X. Li, "Ground subsidence and surface cracks evolution from shallow-buried close-distance multi-seam mining: a case study in bulianta coal mine," Rock Mechanics and Rock Engineering, vol. 52, no. 2, pp. 2835-2852, 2019.

[10] W. Yu and K. Li, "Deformation mechanism and control technology of surrounding rock in the deep-buried large-span chamber," Geofluids, vol. 2020, no. 5, Article ID 8881319, 22 pages, 2020.

[11] W. Yu, B. Pan, F. Zhang, S. Yao, and F. Liu, "Deformation characteristics and determination of optimum supporting time of alteration rock mass in deep mine," KSCE Journal of Civil Engineering, vol. 23, no. 11, pp. 4921-4932, 2019.

[12] H. Yin, L. Lefticariu, J. Wei, J. Guo, Z. Li, and Y. Guan, "In situ dynamic monitoring of stress revolution with time and space under coal seam floor during longwall mining," Environmental Earth Sciences, vol. 75, no. 18, p. 1249, 2016.

[13] F. Li, M. Bi, J. Tian, and S. Fang, "The dynamic damage mechanisms and failure modes of coal-rock masses under the action of high order P-waves," Shock and Vibration, vol. 2018, pp. 1-11, Article ID 5386123, 2018.

[14] H. Han, J. Xu, X. Wang, J. Xie, and Y. Xing, "Method to calculate working surface abutment pressure based on key strata theory," Advances in Civil Engineering, vol. 2019, Article ID 7678327, 20 pages, 2019.

[15] F. Gao, D. Stead, and H. Kang, "Numerical simulation of squeezing failure in a coal mine roadway due to mining-induced stresses," Rock Mechanics and Rock Engineering, vol. 48, no. 4, pp. 1635-1645, 2015.
[16] C. P. Lu, G. J. Liu, H. Y. Wang, and J. H. Xue, "Numerical investigation of rock burst effect of shock wave on underground roadway," Shock and Vibration, vol. 2015, Article ID 867582, 10 pages, 2015.

[17] L. S. Jiang, K. Peng, J. Shu, and K. Fan, "Numerical analysis of support designs based on a case study of a longwall entry," Rock Mechanics and Rock Engineering, vol. 52, no. 9, 12 pages, 2019.

[18] Z.-L. Li, L.-M. Dou, W. Cai, G.-F. Wang, Y.-L. Ding, and Y. Kong, "Mechanical analysis of static stress within faultpillars based on a voussoir beam structure," Rock Mechanics and Rock Engineering, vol. 49, no. 3, pp. 1097-1105, 2016.

[19] B. Jiang, L. Wang, Y. Lu, S. Gu, and X. Sun, "Failure mechanism analysis and support design for deep composite soft rock roadway: a case study of the yang cheng coal mine in China," Shock and Vibration, vol. 2015, Article ID 452479, 14 pages, 2015.

[20] C. Q. Wang, "Research for the law of coal cross overlying goafspillar's pressure during short-distance coal seam's mining," Journal of China Coal Society, vol. 32, no. 2, pp. 35-44, 2006.

[21] G. Yang and X. He, "Safety coal mining technology with partial coal pillar," Coal Science and Technology, vol. 29, no. 10, pp. 16-19, 2001.

[22] J. Ju, J. Xu, and W. Zhu, "Influence of overlying key strata structure pre-sliding on support failure disaster while mining in the lower coal seam cut across below the upper adjacent coal pillar under shallow cover," Journal of China Coal Society, vol. 40, no. 9, pp. 2033-2039, 2015.

[23] J. F. Ju, J. L. Xu, W. B. Zhu, and X. Wang, "Mechanism of strong strata behaviors during the working face out of the upper dip coal pillar in contiguous seams," Journal of China Coal Society, vol. 35, no. 1, pp. 15-20, 2010.

[24] J. Ju, J. Xu, and W. Zhu, "Longwall chock sudden closure incident below coal pillar of adjacent upper mined coal seam under shallow cover in the Shendong coalfield," International Journal of Rock Mechanics and Mining Sciences, vol. 77, pp. 192-201, 2015.

[25] R. Gao, B. Yu, and X. Meng, "Stress distribution and surrounding rock control of mining near to the overlying coal pillar in the working face," International Journal of Mining Science and Technology, vol. 29, no. 6, pp. 881-887, 2019.

[26] B. Yu, "Structural evolution of breaking roof group of multiple coal seams and its influence on lower coal seam mining," Journal of China Coal Society, vol. 40, no. 2, pp. 261-266, 2015.

[27] D. Adhikary, M. Khanal, C. Jayasundara, and R. Balusu, "Deficiencies in 2D simulation: a comparative study of $2 \mathrm{D}$ versus 3D simulation of multi-seam longwall mining," Rock Mechanics and Rock Engineering, vol. 49, no. 6, pp. 2181-2185, 2015.

[28] B. Ghabraie, G. Ren, and J. V. Smith, "Characterising the multi-seam subsidence due to varying mining configuration, insights from physical modelling," International Journal of Rock Mechanics and Mining Sciences, vol. 93, pp. 269-279, 2017.

[29] C. Tian, X. Yang, H. Sun, Y. Liu, and Q. Hu, "Experimental study on the overburden movement and stress evolution in multi-seam mining with residual pillars," Energy Science \& Engineering, vol. 7, no. 6, pp. 3095-3110, 2019.

[30] Q. Huang and J. Cao, "Research on coal pillar malposition distance based on coupling control of three-field in shallow buried closely spaced multi-seam mining, China," Energies, vol. 12, no. 3, p. 462, 2019. 
[31] M. Sun, X. Zhang, W. Zheng, and X. Zhang, "Study on causing disaster and removing danger for stress concentration of overlying residual coal pillar in ultra-close multi-seam," Geotechnical and Geological Engineering, vol. 37, no. 1, pp. 4009-4017, 2019.

[32] W. Shen, L. Dou, H. He, and G. Zhu, "Rock burst assessment in multi-seam mining: a case study," Arabian Journal of Geosciences, vol. 10, no. 8, p. 196, 2017.

[33] S. Q. He, D. Z. Song, Z. L. Li, et al. "Precursor of Spatiotemporal evolution law of MS and AE activities for rock burst warning in steeply inclined and extremely thick coal seams under caving mining condition," Rock Mechanics and Rock Engineering, vol. 52, no. 7, pp. 2415-2435, 2019.

[34] T.-B. Zhao, W.-Y. Guo, Y.-L. Tan, Y.-C. Yin, L.-S. Cai, and J.-F. Pan, "Case studies of rock bursts under complicated geological conditions during multi-seam mining at a depth of 800 m," Rock Mechanics and Rock Engineering, vol. 51, no. 5, pp. 1539-1564, 2018.

[35] Z. L. Li, L. M. Dou, G. Wang, W. Cai, J. He, and Y. Ding, "Rock burst characteristics and mechanism induced within an island pillar coalface with hard roof," Journal of Mining \& Safety Engineering, vol. 41, no. 4, pp. 519-524, 2014.

[36] Z. L. Xu, Elastic Mechanics Brief Tutorial, Higher Education Press (HEP), Beijing, China, 2013.

[37] T. He, Z. Huang, C. Li, F. Luo, and D. Wang, “Temporal and spatial evolution characteristics of lateral coal stress in fully mechanized top coal seam," Journal of Mining \& Safety Engineering, vol. 35, no. 1, pp. 100-105, 2018.

[38] H. He, L. Dou, S. Gong, J. He, Y. Zheng, and X. Zhang, "Microseismic and electromagnetic coupling method for coal bump risk assessment based on dynamic static energy principles," Safety Science, vol. 114, pp. 30-39, 2019.

[39] L. Dou, T. Chen, S. Gong, H. He, and S. Zhang, "Rockburst hazard determination by using computed tomography technology in deep workface," Safety Science, vol. 50, no. 4, pp. 736-740, 2012. 